\title{
Erratum to: Thermostability enhancement of chitosanase CsnA by fusion a family 5 carbohydrate-binding module
}

\author{
Yujuan Han $\cdot$ Peixin Gao $\cdot$ Wengong Yu $\cdot$ Xinzhi Lu
}

Published online: 4 December 2017

(C) Springer Science+Business Media B.V. 2017

Erratum to: Biotechnol Lett

DOI 10.1007/s10529-017-2406-2

In Table 1 as published, some of the data were wrong. The corrected Table 1 is shown here.

The online version of the original article can be found under doi:10.1007/s10529-017-2406-2.

Y. Han · P. Gao · W. Yu · X. Lu ( $ه)$

Key Laboratory of Glycoscience \& Glycotechnology of Shandong Province; Key Laboratory of Marine Drugs, Chinese Ministry of Education; Laboratory for Marine Drugs and Bioproducts, Qingdao National Laboratory for Marine Science and Technology; School of Medicine and Pharmacy, Ocean University of China, 5 Yushan Road, Qingdao 266003, China

e-mail: luxinzhi@ouc.edu.cn

\section{Lu}

Department of Glycobiology, School of Medicine and Pharmacy, Ocean University of China, 5 Yushan Road, Qingdao 266003, China
In addition, according to the corrected Table 1, the sentence "the $k_{c a t} / K_{m}$ of CsnA-CBM5 was higher than that of WT by $143 \%$ " in the part of "The kinetic parameters and specific activity" in the Results part should be changed to "the $k_{c a t} / K_{m}$ of CsnA-CBM5 was higher than that of WT by $110 \%$ ". 
Table 1 Kinetic parameters and specific activities of CsnA, CsnA-CBM5, CsnA-CBM32 and CsnA-CBM35

\begin{tabular}{llllll}
\hline Enzyme & $K_{m}(\mathrm{~g} / \mathrm{l})$ & $V_{m}(\mu \mathrm{M} / \mathrm{s})$ & $K_{\text {cat }}\left(\mathrm{s}^{-1}\right)$ & $K_{\text {cat }} / K_{m}(\mathrm{l} / \mathrm{g} / \mathrm{s})$ & ${\text { Specific activity }(\mathrm{U} / \mu \mathrm{mol})^{\mathrm{a}}}^{2}$ \\
\hline CsnA & $2.8 \pm 0.32$ & $0.27 \pm 0.02$ & $25 \pm 0.8$ & 8.9 & 7660 \\
CsnA-CBM5 & $1.7 \pm 0.11$ & $0.26 \pm 0.05$ & $16 \pm 1$ & 9.4 & 7777 \\
CsnA-CBM32 & $1.7 \pm 0.06$ & $0.20 \pm 0.02$ & $5.9 \pm 0.3$ & 3.5 & 3040 \\
CsnA-CBM35 & $1.3 \pm 0.01$ & $0.14 \pm 0.01$ & $4.2 \pm 0.1$ & 3.2 & 4580 \\
\hline
\end{tabular}

${ }^{a}$ Values are means \pm standard deviations 